\title{
Rapid and sensitive analysis of benzyl isothiocyanate in peel, pulp, and seeds of Carica papaya Linn. by headspace gas chromatography-mass spectrometry
}

\author{
Yinzheng Ma ${ }^{1}$ - Yingying Wen ${ }^{2}$. Jinping Chen ${ }^{3} \cdot$ Yunxia Zhang ${ }^{4,5} \cdot$ Haiying Zhang ${ }^{4}$. Jinlei Sui ${ }^{4} \cdot$ Guohui $\mathrm{Yi}^{4}$. \\ Xiaowen $\mathrm{He}^{4,5}$
}

Received: 5 November 2020 / Accepted: 9 February 2021 / Published online: 25 February 2021

(c) The Author(s) $2021 \quad$ OPEN

\begin{abstract}
A rapid and sensitive headspace gas chromatography-mass spectrometry (HS-GC-MS) method was established for the determination of benzyl isothiocyanate (BITC) in the peel, pulp, and seeds of Carica papaya Linn. Tween 80 solution with a concentration of $0.002 \%(w / v)$ was chosen as a headspace medium for solving the poor solubility of BITC in water without using organic solvents and ensuring high headspace efficiencies. Extraction parameters had been evaluated and optimized by using an orthogonal design with an $\mathrm{OA}_{9}\left(3^{4}\right)$ table. Optimal headspace conditions were obtained when vials were equilibrated at $80^{\circ} \mathrm{C}$ for $20 \mathrm{~min}$ at a stirring speed of $375 \mathrm{rpm}$. The calibration curve obtained by using GC-MS was linear in a concentration range of $10-320 \mathrm{ng} / \mathrm{mL}$. The recoveries of peel, pulp, and seeds ranged from 97.3 to $100.6 \%$ with RSDs less than $3.0 \%$. The method is simple, rapid, sensitive, and environmentally friendly. It is suitable for analyzing BITC in papaya fruit and is expected to have important application potential in the extraction of water-insoluble volatile components in foods, plants, medicines, and other samples.
\end{abstract}

Keywords Carica papaya Linn. Benzyl isothiocyanate · HS-GC-MS · Tween $80 \cdot$ Environmentally friendly

\section{Introduction}

Carica papaya Linn., a tropical plant belonging to Caricaceae of Brassicales, is widely cultivated in tropical and subtropical areas. It is one of the most productive fruits on Hainan Island of southern China. All parts of papaya including leaves, roots, barks, peel, pulp, and seeds have biological activities such as antiviral, anticancer, antibacterial, anti-fungal, anti-inflammatory, and antioxidant [1-3].

Papaya fruit is healthy and delicious. It contains a variety of amino acids and trace elements. Papaya fruit has an active ingredient called benzyl isothiocyanate (BITC), which is an isothiocyanate (ITC). ITCs naturally occur in abundance in cruciferous vegetables such as broccoli, watercress, Brussels sprouts, cabbage, and cauliflower. They have been reported to have human health-promoting properties, such as antioxidative, anti-inflammatory, and anticancer effects [4-6]. Nowadays, BITC has also become a research hotspot for its anticancer, antibacterial, and other activities [7-9]. In 2017, our group reported the antifungal activity of BITC in papaya seeds against Candida spp. [10]. BITC contents in the peel, pulp, and seeds of papaya fruit will change during ripening. BITC is important in terms of both nutritional and active

Yinzheng Ma and Yingying Wen are contributed equally to this work.

$\triangle$ Xiaowen He, xiaowen_he@126.com | ${ }^{1}$ School of Public Health, Hainan Medical University, Haikou 571199, China. ${ }^{2}$ School of Tropical and Laboratory Medicine, Hainan Medical University, Haikou 571199, China. ${ }^{3}$ Institute of Tropical Bioscience and Biotechnology, Chinese Academy of Tropical Agricultural Sciences, Haikou 571101, China. ${ }^{4}$ Public Research Laboratory, Hainan Medical University, Haikou 571199, China. ${ }^{5}$ Key Laboratory of Emergency and Trauma of Ministry of Education, Hainan Medical University, Haikou 571199, China. 
ingredients. It is necessary to monitor the contents of BITC in papaya fruit.

Currently, analysis of BITC in papaya fruit is mainly performed by chromatography. For this method, Samples are usually pretreated before analysis to achieve the purpose of separation, purification, and enrichment of BITC. Traditional extraction methods, such as simultaneous distillation, steam distillation, and solvent extraction, have been applied to extract BITC in papaya $[9,11,12]$. However, these methods are generally time-consuming and laborious with low sensitivity and require a large amount of toxic and environmentally unfriendly organic solvents. Alternatively, headspace solid-phase microextraction (HS-SPME) has been applied to analyze BITC in papaya pulp [13]. However, materials used in HS-SPME are expensive and short-lived with usually inevitable residuals. Therefore, developing a rapid, accurate, highly selective, and environmentally friendly sample pretreatment method is essential for the analysis of BITC in papaya fruit.

Headspace (HS) has the characteristics of easy to install, low cost, less pollution to gas chromatography-mass spectrometry (GC-MS) systems, fast analysis, and high sensitivity. It has been used to determine volatile components in foods, plants, and medicines [14-16]. The rational selection of HS media is the key to the HS method. An ideal HS medium should not only dissolve samples and analytes, but also have good HS efficiency. Water is an ideal medium with good HS efficiency. However, water is not suitable for being directly used as an HS medium for BITC since BITC has poor solubility in water. Although other traditional matrix media, such as $\mathrm{N}, \mathrm{N}$-dimethylformamide (DMF), dimethyl sulfoxide (DMSO), N,N-dimethylacetamide (DMA), can be used as $\mathrm{HS}$ media for BITC, they are volatile and may cause too much pressure thus affect the headspace efficiency of BITC at HS temperature., the volatile organic solvents may contaminate the MS system and shorten the lifetime of the column.To increase the solubility of BITC in water, thus improving the sensitivity of the method,tween 80 , which is non-volatile and interference-free for MS systems, can be added into water.

In this study, we proposed the use of HS-GC-MS to determine BITC in the peel, pulp, and seeds of papaya with a $0.002 \%(w / v)$ tween 80 solution as the HS medium. An orthogonal design was employed to assist in quickly and reliably finding optimum extraction conditions. The HS-GC-MS method is simple, rapid, sensitive, and environmentally friendly. It is suitable for the analysis of BITC in papaya fruit.

\section{Materials and methods}

\subsection{Samples, chemicals, and standard solutions}

Papaya fruits $(\mathrm{S} 1, \mathrm{~S} 5, \mathrm{~S} 6)$ used in the experiment were purchased from a fruit market in Haikou, Hainan, China.
Papaya fruits $(\mathrm{S} 2, \mathrm{~S} 3, \mathrm{~S} 4)$ were obtained from the same tree in Ding'an County, Hainan in November $2018.10 \mathrm{~g}$ of fresh papaya peel, pulp, and seeds were separately added into $50 \mathrm{~mL}$ of $0.002 \%(w / v)$ tween 80 aqueous solutions. After homogenization using a JYL-C902D Juicer (Jiuyang Co. Ltd., Jinan, Shandong, China), the solutions were placed into $100 \mathrm{~mL}$ volumetric flasks. The inner wall of the juicer was washed for three times and the moistening solutions were combined into the volumetric flasks. Sample solutions were prepared from the above solutions by diluting with appropriate amounts of $0.002 \%$ tween 80 solutions.

Benzyl isothiocyanate [B140288-25 g, $>98.0 \%$ (GC)] was purchased from Aladdin (Shanghai, China). Tween 80 was provided by Tianjin Damao Chemical Reagent Factory (Tianjin, China). Ultrapure water used throughout the work was obtained by purifying demineralized water in a CASCADA LS MK2 system (PALL Corporation, New York, USA).

A standard stock solution containing $3.2 \mathrm{mg} / \mathrm{mL}$ of BITC was prepared by dissolving the required amounts of standard in a $0.2 \%(w / v)$ tween 80 aqueous solution. This solution was stored in a refrigerator at $4{ }^{\circ} \mathrm{C} .1 \mathrm{~mL}$ of the stock solution was placed in a $100 \mathrm{~mL}$ volumetric flask and water was added to make a constant volume. Then the standard solution containing BITC at a concentration of $32 \mu \mathrm{g} /$ $\mathrm{mL}$ was obtained (with $0.002 \%$ tween 80 ). Working solutions containing $10-320 \mathrm{ng} / \mathrm{mL}$ of BITC were prepared by serially diluting the above standard solution with $0.002 \%$ tween 80 solutions.

\subsection{Instrumentation}

BITC was measured by using a Shimadzu GC-MS-QP2010Plus system (Shimadzu, Kyoto, Japan), equipped with a Gerstel MPS2 Multi-Purpose Sampler (Tegent, Germany). Data were processed and elaborated with Shimadzu GC-MS Solution software (Shimadzu, v 2.70, Kyoto, Japan). The separation of BITC was achieved on a fused-silica capillary column coated with a $5 \%$ phenylarylene/95\% dimethyl polysiloxane stationary phase (ZB-5MS, $30 \mathrm{~m} \times 0.25 \mathrm{~mm} \times 0.25 \mu \mathrm{m}$, Phenomenex, Torrance, CA, USA). Helium (purity $>99.999 \%$ ) was used as a carrier gas at a flow rate of $1.0 \mathrm{~mL} / \mathrm{min}$ in a split mode (20:1). The column temperature was maintained at $80^{\circ} \mathrm{C}$ and then programmed to $150^{\circ} \mathrm{C}$ at a heating rate of $5^{\circ} \mathrm{C} /$ min, and was finally increased to $210^{\circ} \mathrm{C}$ at a rate of $20^{\circ} \mathrm{C} /$ $\mathrm{min}$ for $1 \mathrm{~min}$. Temperatures of both injector and connector were maintained at $250^{\circ} \mathrm{C}$. Operating parameters of MS:electron impact (El)at $70 \mathrm{eV}$ and the temperature of ion source was $210^{\circ} \mathrm{C}$. The retention time and the fragment ions were identified by injecting the standard solution in full-scan mode $(\mathrm{m} / \mathrm{z} 50-550)$. Quantification was performed by calculating the absolute peak areas in SIM 
mode with quantitation icon $(\mathrm{m} / \mathrm{z}$ 91) and qualifying icons $(m / z 65,149)$.

\subsubsection{HS procedure}

$10 \mathrm{~mL}$ of standard or sample solutions were added into a $20 \mathrm{~mL}$ headspace vial. The vial was closed with a PTFE/ silicone rubber pad and a magnetic cap. Then it was equilibrated at $80^{\circ} \mathrm{C}$ for $20 \mathrm{~min}$ at a rate of $375 \mathrm{rpm}$. Finally, a $500 \mu \mathrm{L}$ of injection volume from headspace was injected into GC-MS for analysis.

\section{Results and discussion}

\subsection{Selection of HS medium}

The rational selection of HS media is the key to the HS-GC-MS method. An ideal HS medium should not only dissolve the samples and analytes, but also has good HS efficiency, that is, high sensitivity. Water is an ideal matrix medium for water-soluble components and shows good HS efficiency. For water-insoluble samples and analytes, traditional HS media such as DMA and DMSO can produce wide chromatographic peaks in the process of analysis due to their interferences with analytes, which reduce the life of chromatographic columns, even contaminate the MS system. BITC has poor solubility in water, and water is not suitable to be directly used as an HS matrix medium.

Tween 80 is a surfactant that can encapsulate BITC into the micelle of tween 80 solutions. In this study, a $0.2 \%$ tween 80 solution was used to dissolve high-content of BITC, which was then diluted to $0.002 \%$. After dilution, the concentration of the solution was still above the critical micelle concentration $(0.0014 \%)$ of tween 80 solution, thus would not destroy the solubilization of the micelle. At the same time, the content of tween 80 in the solution was low, so that there were few interferences. Herein, a $0.002 \%$ tween 80 solution was chosen as the HS medium. It not only solved the poor solubility of BITC in water, but also ensured high HS efficiency. Meanwhile, the disadvantages of using other organic solvents such as DMA and DMSO were avoided.

\subsection{Orthogonal design for HS optimization}

The effects of four parameters on HS performance were studied, including sample volume, HS temperature, equilibrium time, and stirring speed. The ranges and intervals of the four variables were determined by a one-factor analysis of variable preliminary experiments. The final factors and levels were sample volume $(2 \mathrm{~mL}, 6 \mathrm{~mL}, 10 \mathrm{~mL})$, HS temperature $\left(60{ }^{\circ} \mathrm{C}, 70{ }^{\circ} \mathrm{C}, 80^{\circ} \mathrm{C}\right)$, equilibrium time (10 min, $20 \mathrm{~min}, 30 \mathrm{~min}$ ), and stirring speed $(0,375 \mathrm{rpm}$, $750 \mathrm{rpm})$. In order to optimize the factors that affect the extraction efficiency, an $\mathrm{OA}_{9}\left(3^{4}\right)$ orthogonal design was established, and a total of nine experiments were randomly conducted. The peak area of BITC was considered as the experimental response. The experiments and results were listed in Table 1. The optimal extraction conditions obtained by orthogonal design were used to extract BITC from papaya fruit.

From the results of the experimental response range analysis as shown in Table 1, it can be seen that the order of influence of each factor on the extraction was HS temperature $>$ sample volume $>$ equilibrium time $>$ stirring speed. HS temperature had the greatest influence on the extraction efficiency.

\subsection{Effect of sample volume}

In general, the content of BITC increases with the increase of sample volume. However, it is difficult to reach equilibrium if the sample volume is too large. Thus, in this study, samples with volumes of 2,6 , and $10 \mathrm{~mL}$ were initially evaluated. The results showed that the peak area of BITC was increased as the sample volume was increased. The volume of $10 \mathrm{~mL}$ was finally selected.

\subsection{Effect of HS temperature}

The HS temperature had the greatest influence on the extraction efficiency. By increasing the HS temperature from 60 to $80^{\circ} \mathrm{C}$, the peak area correspondingly increased greatly. The HS temperature was not evaluated above $80^{\circ} \mathrm{C}$ because a large amount of water vapor was generated. Therefore, the final equilibrium temperature was set at $80^{\circ} \mathrm{C}$

\subsection{Effect of equilibrium time}

In order to ensure better reproducibility, it is necessary to select an equilibrium time for gas-liquid equilibrium. The effect of extraction time was studied by varying between 10 and $30 \mathrm{~min}$. As shown in Table 1, the extraction balance could be reached within $20 \mathrm{~min}$, and extending the equilibrium time had no significant effect on the extraction efficiency. Based on this result, 20 min were selected for subsequent studies. 
Table 1 Range analysis results of experimental response

\begin{tabular}{|c|c|c|c|c|c|}
\hline \multirow[t]{2}{*}{ Test number } & \multicolumn{4}{|l|}{ Factor } & \multirow[t]{2}{*}{$A_{\text {BITC }}$} \\
\hline & $A$ & B & $C$ & $\mathrm{D}$ & \\
\hline 1 & 3 & 2 & 3 & 1 & $2,099,630$ \\
\hline 2 & 3 & 3 & 2 & 2 & $2,957,403$ \\
\hline 3 & 2 & 1 & 3 & 2 & $1,468,731$ \\
\hline 4 & 2 & 3 & 1 & 1 & $2,524,041$ \\
\hline 5 & 2 & 2 & 2 & 3 & $1,798,749$ \\
\hline 6 & 1 & 3 & 3 & 3 & $1,884,262$ \\
\hline 7 & 1 & 1 & 2 & 1 & $1,052,493$ \\
\hline 8 & 3 & 1 & 1 & 3 & $1,274,703$ \\
\hline 9 & 1 & 2 & 1 & 2 & $1,551,532$ \\
\hline K1 & $4,488,287$ & $3,795,927$ & $5,350,276$ & $5,676,164$ & \\
\hline K2 & $5,791,521$ & $5,449,911$ & $5,808,645$ & $5,977,666$ & \\
\hline K3 & $6,331,736$ & $7,365,706$ & $5,452,623$ & $4,957,714$ & \\
\hline$\Sigma \mathrm{K} 1$ & $1,496,096$ & $1,265,309$ & $1,936,215$ & $1,892,055$ & \\
\hline$\Sigma \mathrm{K} 2$ & $1,930,507$ & $1,816,637$ & $1,783,425$ & $1,992,555$ & \\
\hline$\Sigma \mathrm{K} 3$ & $2,110,579$ & $2,455,235$ & $1,817,541$ & $1,652,571$ & \\
\hline Range & 614,483 & $1,189,926$ & 152,790 & 339,984 & \\
\hline Primary and secondary oder & $B>A>D>C$ & & & & \\
\hline Optimization level & $\mathrm{A}_{3}$ & $\mathrm{~B}_{3}$ & $\mathrm{C}_{2}$ & $\mathrm{D}_{2}$ & \\
\hline Optimization combination & $A_{3} B_{3} C_{2} D_{2}$ & & & & \\
\hline
\end{tabular}

\subsection{Effect of stirring speed}

Generally, agitation of the sample improves mass transfer in the aqueous phase, so that the time required to reach equilibrium is reduced. Since the maximum stirring speed of the Multi-Purpose Sampler in this study is $750 \mathrm{rpm}, 0$, $375 \mathrm{rpm}, 750 \mathrm{rpm}$ were investigated. As shown in Table 1, the stirring speed was the smallest factor affecting the efficiency of HS extraction0. A stirring speed of $375 \mathrm{rpm}$ was sufficient for maximum extraction efficiency. Therefore, the stirring speed of $375 \mathrm{rpm}$ was selected.

\subsection{Validation of the HS-GC-MS method}

The specificity of the method was tested by comparing the blank solution $(0.002 \%$ tween 80 solution), standard solution, and sample solutions after extraction. As shown in Fig. 1, the retention time of BITC standard was identified at 12.0 min. It was clear that BITC showed a symmetrical peak with no obvious interference.
To test the linearity of the proposed method, a sixpoint standard curve was constructed with BITC concentrations ranging from 10 to $320 \mathrm{ng} / \mathrm{mL}$. Good linearity was obtained between the peak-area $(A)$ of BITC and corresponding concentrations $(c)$ of BITC with a regression equation of $A=1108 c-6930$, a correlation coefficient $(r)$ of $0.9997 .95 \%$ Confidence intervals of the slope and intercept were $1108 \pm 12,-6930 \pm 1825$, respectively. $P$ value $<0.001$.

Based on the GC-MS analysis, the limit of quantification (LOQ) and limit of detection (LOD) were $0.8 \mathrm{ng} / \mathrm{mL}$ and $0.2 \mathrm{ng} / \mathrm{mL}$ calculated by using signal-to-noise ratios $(\mathrm{S} / \mathrm{N})$ of 10 and 3 , respectively.

To assess the repeatability and stability of the developed method, the peel, pulp, and seed solutions of S1 were analyzed in six independent series on the same day. The relative standard deviation (RSD) values of the peak areas for precision were $1.5 \%, 1.5 \%$, and $1.2 \%$ for the peel, pulp, and seeds solutions, respectively. Stability test results showed that sample solutions were stable from 0 to $24 \mathrm{~h}$ at $4{ }^{\circ} \mathrm{C}$ with RSDs of $1.9 \%, 1.7 \%, 1.4 \%$. 


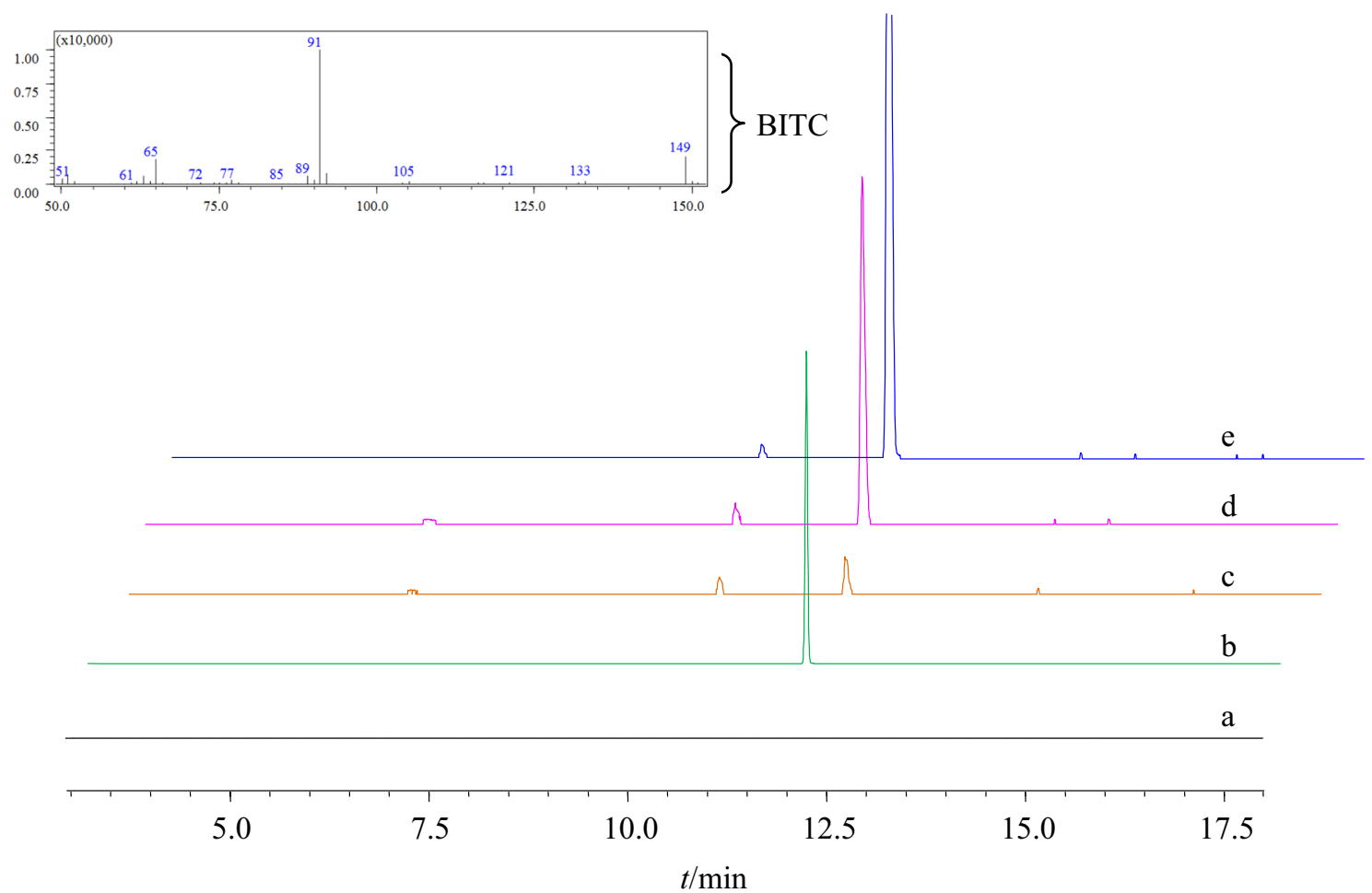

Fig. 1 TIC Chromatograms of blank solution (a), standard solution (b) and sample solutions (papaya pulp-c, papaya peel-d, papaya seeds-e) by HS-GC-MS and MS of BITC

The accuracy of the proposed method was examined as percentages of recovery. Three standard solutions with different concentrations in the linear range $(80 \%, 100 \%$, and $120 \%)$ were added to sample solutions in triplicate. The results of the recovery analysis were provided in Table 2, showing excellent recoveries, ranging from 97.3 to $100.6 \%$ with RSDs of less than $3.0 \%$. Therefore, it can be concluded that the proposed method is accurate and can be applied for the determination of BITC in papaya fruit samples.

\subsection{Determination of BITC in papaya samples}

The applicability of this method to the determination of BITC contents in papaya peel, pulp, and seeds was tested with results shown in Table 3. The concentrations of BITC in seeds were the highest $(238.0-683.0 \mu \mathrm{g} / \mathrm{g})$, followed by in the peel $(1.4-31.0 \mu \mathrm{g} / \mathrm{g})$, and in the pulp were the lowest $(0.2-2.3 \mu \mathrm{g} / \mathrm{g}$ ). SPSS 17.0 (IBM Corp., Chicago, IL, USA) was used for statistical analysis. The concentrations of BITC in the three parts of papaya fruit were statistically significant $(P<0.05)$.

When the seeds of immature papaya (S1) were white and not plump, the BITC contents in the pulp and peel were significantly higher than that of other papayas, and the BITC content in seeds was the lowest. With the growth of papaya fruit, when the seeds were still white but plumper (S2), the BITC contents in the pulp and peel slightly decreased, while the BITC contents in the seeds increased. When the seeds gradually turned black in color and mature (S3-S6), the BITC contents 
Table 2 Recoveries of BITC in peel, pulp and seeds of Carica papaya $(n=3)$

\begin{tabular}{|c|c|c|c|c|c|c|}
\hline Part & $\begin{array}{l}\text { Original amout } \\
\text { (ng) }\end{array}$ & $\begin{array}{l}\text { Added amout } \\
\text { (ng) }\end{array}$ & $\begin{array}{l}\text { Detected amout } \\
\text { (ng) }\end{array}$ & $\begin{array}{l}\text { Recovery } \\
(\%)\end{array}$ & $\begin{array}{l}\text { Average } \\
\text { recovery } \\
(\%)\end{array}$ & $\begin{array}{l}\text { RSD } \\
(\%)\end{array}$ \\
\hline \multirow[t]{9}{*}{ Peel } & 402.5 & 480.0 & 882.6 & 100.0 & 98.6 & 1.3 \\
\hline & & & 871.2 & 97.6 & & \\
\hline & & & 874.4 & 98.3 & & \\
\hline & 402.5 & 400.0 & 809.9 & 101.8 & 100.3 & 1.6 \\
\hline & & & 797.4 & 98.7 & & \\
\hline & & & 803.2 & 100.2 & & \\
\hline & 402.5 & 320.0 & 714.7 & 97.6 & 99.5 & 1.9 \\
\hline & & & 726.8 & 101.3 & & \\
\hline & & & 721.0 & 99.5 & & \\
\hline \multirow[t]{9}{*}{ Pulp } & 81.5 & 96.0 & 177.7 & 100.3 & 100.6 & 1.3 \\
\hline & & & 177.2 & 99.6 & & \\
\hline & & & 179.4 & 102.0 & & \\
\hline & 81.5 & 80.0 & 160.1 & 98.2 & 99.3 & 1.7 \\
\hline & & & 160.2 & 98.4 & & \\
\hline & & & 162.4 & 101.2 & & \\
\hline & 81.5 & 64.0 & 142.2 & 94.9 & 97.3 & 2.4 \\
\hline & & & 145.2 & 99.6 & & \\
\hline & & & 143.8 & 97.3 & & \\
\hline \multirow[t]{9}{*}{ Seeds } & 856.0 & 1020.0 & 1880.7 & 100.5 & 99.9 & 1.0 \\
\hline & & & 1881.7 & 100.6 & & \\
\hline & & & 1863.6 & 98.8 & & \\
\hline & 856.0 & 850.0 & 1689.2 & 98.0 & 98.6 & 1.7 \\
\hline & & & 1683.1 & 97.3 & & \\
\hline & & & 1710.2 & 100.5 & & \\
\hline & 856.0 & 680.0 & 1527.0 & 98.7 & 99.1 & 1.2 \\
\hline & & & 1539.1 & 100.5 & & \\
\hline & & & 1524.2 & 98.3 & & \\
\hline
\end{tabular}

in the peel significantly decreased, and the BITC contents in the seeds significantly increased. In all stages of papaya growth, BITC levels in the pulp were lowest and decreased during fruit development and ripening, while BITC levels in the seeds were highest and increased during fruit ripening. The results of this study revealed the changing patterns of BITC in three parts of a papaya fruit at different growth stages. They were generally consistent with the changing patterns reported in previous literature [9].

\subsection{Method performance comparison}

In Table 4, the present method was compared with some reported methods, which have been applied to the extraction and analysis of BITC in papaya fruit [9-13, 17, 
Table 3 Results of determination of BITC in samples $(n=3)$

\begin{tabular}{|c|c|c|c|c|}
\hline No. & Part & Color (shape) & $\begin{array}{l}\text { Content, } \\
\text { mean } \pm S D \\
(\mu \mathrm{g} / \mathrm{g})\end{array}$ & $R S D(\%)$ \\
\hline \multirow[t]{3}{*}{ S1 } & Peel & Green & $31.0 \pm 0.73$ & 2.4 \\
\hline & Pulp & White & $2.3 \pm 0.04$ & 1.8 \\
\hline & Seeds & White (not plump) & $238.0 \pm 5.52$ & 2.4 \\
\hline \multirow[t]{3}{*}{ S2 } & Peel & Green & $5.8 \pm 0.02$ & 0.4 \\
\hline & Pulp & White & $0.5 \pm 0.01$ & 2.0 \\
\hline & Seeds & White (plump) & $462.0 \pm 1.56$ & 0.4 \\
\hline \multirow[t]{3}{*}{ S3 } & Peel & Yellow & $1.5 \pm 0.03$ & 2.3 \\
\hline & Pulp & Deep yellow to orange & $0.3 \pm 0.03$ & 1.3 \\
\hline & Seeds & Black with a little white & $535.6 \pm 3.48$ & 0.7 \\
\hline \multirow[t]{3}{*}{ S4 } & Peel & Yellow & $1.4 \pm 0.002$ & 0.2 \\
\hline & Pulp & Deep yellow to orange & $0.2 \pm 0.0004$ & 0.3 \\
\hline & Seeds & Black & $641.6 \pm 6.12$ & 1.0 \\
\hline \multirow[t]{3}{*}{ S5 } & Peel & Yellow & $2.3 \pm 0.02$ & 1.0 \\
\hline & Pulp & Deep yellow to orange & $0.2 \pm 0.002$ & 1.1 \\
\hline & Seeds & Black & $615.4 \pm 17.59$ & 2.9 \\
\hline \multirow[t]{3}{*}{ S6 } & Peel & Yellow & $1.6 \pm 0.02$ & 0.2 \\
\hline & Pulp & Deep yellow to orange & $0.2 \pm 0.003$ & 2.1 \\
\hline & Seeds & Black & $683.0 \pm 4.81$ & 0.8 \\
\hline
\end{tabular}

18]. Extraction procedures such as simultaneous distillation and solvent extraction are time-consuming, requiring a large number of samples and unfriendly organic solvents such as diethyl ether, methanol, and $n$-hexane. In addition, these procedures are mainly performed using open systems, which leads to the loss of volatile
BITC and further results in inaccurate results. Although hydrodistillation (steam distillation) and HS-SPME do not use organic solvents, hydrodistillation requires a large number of samples and long-time extraction, and HS-SPME has disadvantages of using high-cost extraction fibers and residual effects. The HS-GS-MS method was demonstrated to be a simple, fast, cost-effective, and environmentally benign option for analyzing BITC in papaya peel, pulp, and seeds.

\section{Conclusion}

In this study, an orthogonal design was used to develop an HS-GC-MS method using a $0.002 \%$ Tween 80 solution as the HS medium for the determination of BITC in papaya peel, pulp, and seeds. This method can be used for determining BITC contents in all parts of the papaya fruit with low LOD, wide linear range, and high recovery. The results revealed the changing patterns of BITC in papaya fruit at different maturity stages. This method was proved to be simple, rapid, sensitive, precise, and environmentalfriendly. Importantly, this extraction method does not require using organic solvents or any special equipment. The HS-GC-MS method using a $0.002 \%$ tween 80 solution as the HS medium is expected to have important application potential in the extraction of water-insoluble volatile components in foods, plants, medicines, and other samples. 


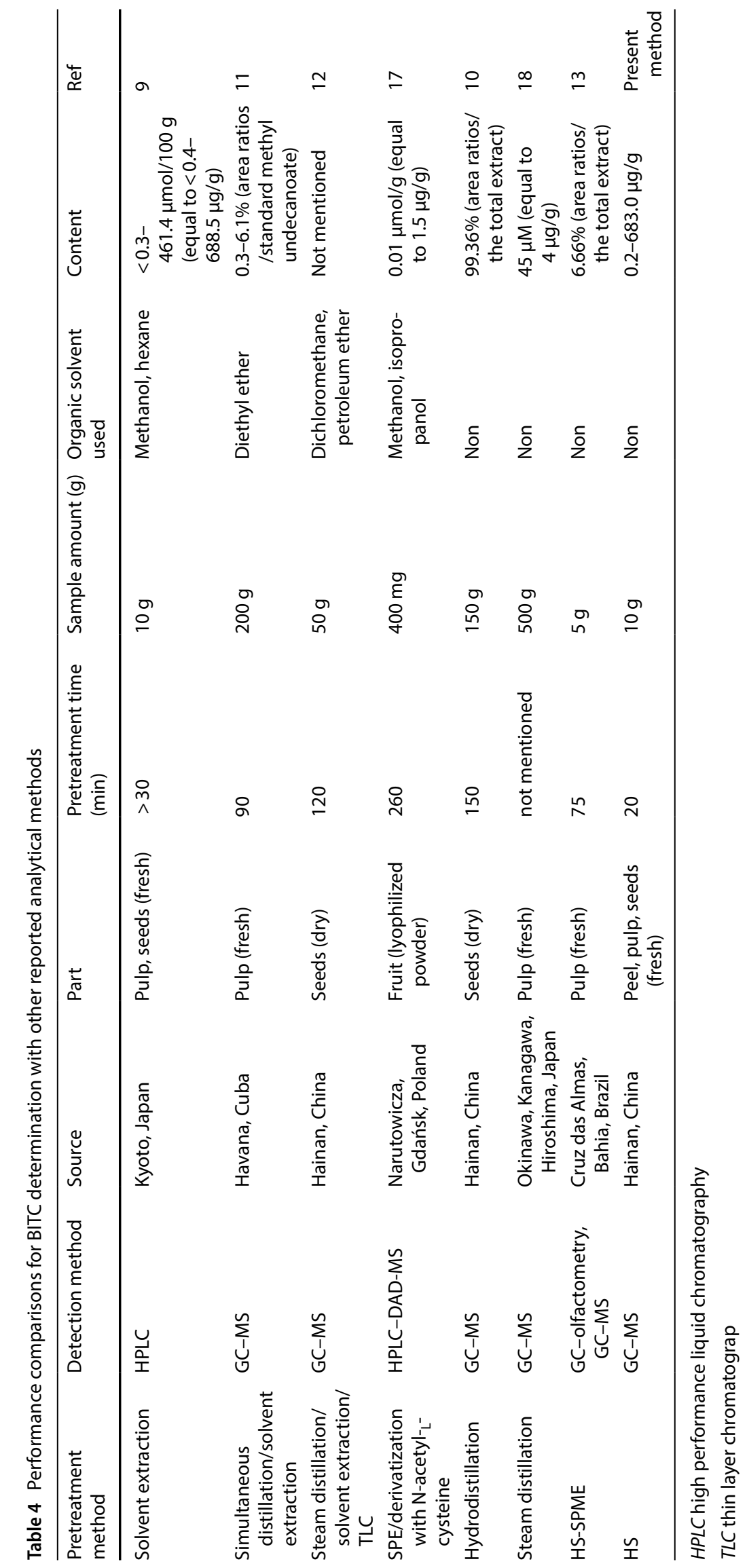


Acknowledgements This research was supported by High level talent project of Hainan Basic and Applied Basic Research Program (Natural Science Field) (2019RC219, 2019RC226); University scientific research project Hainan province (Hnky2019-46).

\section{Compliance with ethical standards}

Conflict of interest The authors declare no conflicts of interest.

Open Access This article is licensed under a Creative Commons Attribution 4.0 International License, which permits use, sharing, adaptation, distribution and reproduction in any medium or format, as long as you give appropriate credit to the original author(s) and the source, provide a link to the Creative Commons licence, and indicate if changes were made. The images or other third party material in this article are included in the article's Creative Commons licence, unless indicated otherwise in a credit line to the material. If material is not included in the article's Creative Commons licence and your intended use is not permitted by statutory regulation or exceeds the permitted use, you will need to obtain permission directly from the copyright holder. To view a copy of this licence, visit http://creativecommons .org/licenses/by/4.0/.

\section{References}

1. Vij T, Prashar Y (2015) A review on medicinal properties of Carica papaya Linn. Asian Pac J Trop Dis 1:1-6

2. Asghar N, Naqvi SAR, Hussain Z, Rasool N, Khan ZA, Shahzad SA, Sherazi TA, Janjua MRSA (2016) Compositional difference in antioxidant and antibacterial activity of all parts of theCarica papaya using different solvents. Chem Cent J 10:1-11

3. Abdel-Lateef EE, Rabia IA, El-Sayed MM, Abdel-Hameed ES (2018) HPLC-ESI-MS characterization of certain polyphenolic compounds of Carica papaya L. fruit extracts and evaluation of their potential against Murine Schistosomiasis mansoni. Drug Res 68:521-528

4. Wilson $A E$, Bergaentzlé $M$, Bindler $F$, Marchioni $E$, Lintz $A$, Ennahar S (2013) In vitro efficacies of various isothiocyanates from cruciferous vegetables as antimicrobial agents against foodborne pathogens and spoilage bacteria. Food Control 30:318-324

5. Arora R, Arora S, Vig AP (2018) Development of validated hightemperature reverse-phase UHPLC-PDA analytical method for simultaneous analysis of five natural isothiocyanates in cruciferous vegetables. Food Chem 239:1085-1089

6. Huang L, Cai C, Dang W, Lu JH, Hu GF, Gu J (2019) Propyl isothiocyanate induces apoptosis in gastric cancer cells by oxidative stress via glutathione depletion. Oncol Lett 18:5490-5498
7. Azaiez I, Meca G, Manyes L, Fernández-Franzón M (2013) Antifungal activity of gaseous allyl, benzyl and phenyl isothiocyanate in vitro and their use for fumonisins reduction in bread. Food Cont 32:428-434

8. Yang CX, Wu HT, Li XX, Wu HY, Niu TX, Wang XN, Lian R, Zhang GL, Hou HM (2019) Comparison of the inhibitory potential of benzyl isothiocyanate and phenethyl isothiocyanate on Shiga toxin-producing and enterotoxigenic Escherichia coli. LWT 118:108806

9. Nakamura $Y$, Yoshimoto $M$, Murata $Y$, Shimoishi Y, Asai Y, Park EY, Sato K, Nakamura Y (2007) Papaya seed represents a rich source of biologically active isothiocyanate. J Agric Food Chem 55:4407-4413

10. He XW, Ma YZ, Yi GH, Wu JY, Zhou LM, Guo H (2017) Chemical composition and antifungal activity of Carica Papaya Linn. seeds essential oil against Candidaspp. Lett Appl Microbiol 64:350-354

11. Almora K, Pino JA, Hernandez M, Duarte C, Gonzalez J, Roncal E (2004) Evaluation of volatiles from ripening papaya (Carica papaya L. var Maradolroja). Food Chem 86:127-130

12. Li WZ, Du YD, Zhang Y, Chi YZ, Shi ZY, Chen W, Ruan MJ, Zhu HP (2014) optimized formation of benzyl isothiocyanate by endogenous enzyme and its extraction from Carica Papaya Seed. Trop J Pharm Res 13:1303-1311

13. da Rocha RFJ, da Silva Araújo ÍM, de Freitas SM, dos Santos Garruti D (2017) Optimization of headspace solid phase microextraction of volatile compounds from papaya fruit assisted by GC-olfactometry. J Food Sci Technol 54:4042-4050

14. Soria AC, García-Sarrió MJ, Sanz ML (2015) Volatile sampling by headspace techniques. TrAC Trend Anal Chem 71:85-99

15. Xie WQ, Yu KX, Gong YX (2019) Rapid and quantitative determination of urea in milk by reaction headspace gas chromatography. Microchem J 147:838-841

16. Gimeno P, Auguste ML, Handlos V, Nielsen AM, Schmidt S, Lassu $N$, Vogel M, Fischer A, Brenier C, Duperray F (2018) Identification and quantification of ethylene oxide in sterilized medical devices using multiple headspace GC/MS measurement. J Pharm Biomed Anal 158:119-127

17. PilipczukT, Kusznierewicz B, Chmiel T, Przychodzeń W, Bartoszek A (2017) Simultaneous determination of individual isothiocyanates in plant samples by HPLC-DAD-MS following SPE and derivatization with $\mathrm{N}$-acetyl $\mathrm{L}_{\mathrm{L}}$-cysteine. Food Chem 214:587-596

18. Nakamura, T., Murata, Y., Nakamura, Y.; Characterization of benzyl isothiocyanate extracted from mashed green papaya by distillation. Food Chem 299:125118.

Publisher's Note Springer Nature remains neutral with regard to jurisdictional claims in published maps and institutional affiliations. 